Review Article

\title{
The CXCL10/CXCR3 Axis and Cardiac Inflammation: Implications for Immunotherapy to Treat Infectious and Noninfectious Diseases of the Heart
}

\author{
Raffaele Altara, ${ }^{1}$ Ziad Mallat, ${ }^{2,3}$ George W. Booz, ${ }^{1}$ and Fouad A. Zouein ${ }^{4}$ \\ ${ }^{1}$ Department of Pharmacology and Toxicology, School of Medicine, University of Mississippi Medical Center, Jackson, \\ MS 39216-4500, USA \\ ${ }^{2}$ Division of Cardiovascular Medicine, Department of Medicine, University of Cambridge, Cambridge CB20 SZ, UK \\ ${ }^{3}$ Institut National de la Santé et de la Recherche Médicale (Inserm), Unit 970, Paris Cardiovascular Research Center, \\ 75015 Paris, France \\ ${ }^{4}$ Department of Pharmacology and Toxicology, American University of Beirut, Faculty of Medicine, Beirut 1107 2020, Lebanon
}

Correspondence should be addressed to Raffaele Altara; raltara@umc.edu

Received 17 June 2016; Revised 16 August 2016; Accepted 30 August 2016

Academic Editor: Giuseppe A. Sautto

Copyright (C) 2016 Raffaele Altara et al. This is an open access article distributed under the Creative Commons Attribution License, which permits unrestricted use, distribution, and reproduction in any medium, provided the original work is properly cited.

\begin{abstract}
Accumulating evidence reveals involvement of T lymphocytes and adaptive immunity in the chronic inflammation associated with infectious and noninfectious diseases of the heart, including coronary artery disease, Kawasaki disease, myocarditis, dilated cardiomyopathies, Chagas, hypertensive left ventricular (LV) hypertrophy, and nonischemic heart failure. Chemokine CXCL10 is elevated in cardiovascular diseases, along with increased cardiac infiltration of proinflammatory Th1 and cytotoxic T cells. CXCL10 is a chemoattractant for these $\mathrm{T}$ cells and polarizing factor for the proinflammatory phenotype. Thus, targeting the CXCL10 receptor CXCR3 is a promising therapeutic approach to treating cardiac inflammation. Due to biased signaling CXCR3 also couples to antiinflammatory signaling and immunosuppressive regulatory $\mathrm{T}$ cell formation when activated by CXCL11. Numbers and functionality of regulatory $\mathrm{T}$ cells are reduced in patients with cardiac inflammation, supporting the utility of biased agonists or biologicals to simultaneously block the pro-inflammatory and activate the anti-inflammatory actions of CXCR3. Other immunotherapy strategies to boost regulatory $\mathrm{T}$ cell actions include intravenous immunoglobulin (IVIG) therapy, adoptive transfer, immunoadsorption, and low-dose interleukin-2/interleukin-2 antibody complexes. Pharmacological approaches include sphingosine 1-phosphate receptor 1 agonists and vitamin D supplementation. A combined strategy of switching CXCR3 signaling from pro- to anti-inflammatory and improving Treg functionality is predicted to synergistically lessen adverse cardiac remodeling.
\end{abstract}

\section{Introduction}

The chemokine receptor CXCR3 is a Class A seventransmembrane-domain or $\mathrm{G}$ protein-coupled receptor (GPCR) that is involved primarily in chemotaxis of certain immune cells, inhibition of angiogenesis, and Thl cell polarization [1-3]. CXCR3 is expressed by various effector $\mathrm{T}$ lymphocytes, including $\mathrm{CD}^{+} \mathrm{T}$ helper 1 (Th1) cells, $\mathrm{CD}^{+}$ cytotoxic T lymphocytes (CTL), and $\mathrm{CD}^{+}$and $\mathrm{CD} 8^{+}$memory $\mathrm{T}$ cells, as well as monocytes, M1 macrophages, natural killer (NK) cells, subsets of B-cells, mast cells, endothelial cells, and vascular smooth muscle cells [1-4]. CXCR3 couples to $\mathrm{G} \alpha_{\mathrm{i}}$ protein $[5,6]$ and although not extensively studied, it has been shown to activate a number of signaling pathways that are generally associated with GPCRs such as increases in intracellular calcium and activation of MAP kinases and PI3K/Akt signaling $[4,7,8]$. The principal agonists of CXCR3 are CXCL9 (Mig), CXCL10 (IP-10), and CXCL11 (I-TAC). The human equivalent of the murine form of CXCR3 is CXCR3A and unless noted otherwise CXCR3 is used in this review to include both murine and human isoforms. Two additional splice variants of CXCR3 are expressed in humans, CXCR3B and CXCR3-alt. CXCR3B, which couples to $G_{s}$, is the receptor isoform expressed in microvascular endothelial cells and is linked to inhibition of angiogenesis and induction of apoptosis $[2,3]$. Besides CXCL9, CXCL10, 
and CXCL11, CXCR3B and CXCR3 are activated by CXCL4 and CXCL4L1, chemokines that are released by platelets and have been implicated in atherogenesis and acute coronary syndrome $[3,9,10]$. CXCR3-alt is a truncated form of CXCR3 that is selectively activated by CXCL11 [2-4].

CXCR3 is associated with the pathophysiology of Th1type diseases, including infections of various etiologies and autoimmune disorders [1,3]. Although CXCR3 is activated by CXCL9, CXCL10, and CXCL11, the outcome is different with growing evidence that CXCL9 and CXCL10 are essentially proinflammatory, while CXCL11 has anti-inflammatory actions [11, 12]. Over the last decade, numerous studies have documented elevated circulating levels of CXCL10 in wide-ranging infectious and autoimmune diseases, autoimmune encephalomyelitis, Crohn's disease, tuberculosis, thyroid autoimmune diseases, and type 1 diabetes, as well as several cancers [13-18]. Recent evidence from us and others [1] has revealed the importance of the CXCL10/CXCR3 axis in cardiovascular diseases. As discussed elsewhere [11], CXCL9 and CXCL10 are two of only 8-10 chemokines that are sufficient to sustain an inflammatory response. In addition, the homing signature for memory $\mathrm{T}$ cells to the heart from mediastinal lymph nodes is $\mathrm{c}-\mathrm{Met}^{+} \mathrm{CCR} 4^{+} \mathrm{CXCR} 3^{+}$. While $\mathrm{c}$-Met triggering supports cardiotropic $\mathrm{T}$ cell recirculation, CXCR3 and CCR4 engagement via tissue-released CXCL10 and CCL4, respectively, sustains recruitment in heart inflammation $[19,20]$. In this review, we present an overview of the role of CXCL9 and CXCL10 in infectious and noninfectious diseases of the heart and its implications for immunotherapy.

\section{CXCR3 Biased Signaling}

Recently, Zohar et al. [21] showed that CXCL9 and CXCL10 drive effector Th1/Th17 cell polarization via STAT1, STAT4, and STAT5 activation, thereby promoting inflammation. In contrast, CXCL11, which exhibits relatively higher binding affinity for CXCR3, drives development of FOXP3 (forkhead box P3)-negative IL- $10^{\text {high }}$ T regulatory 1 (Tr1) cells and IL- $4{ }^{\text {hi }}$ Th2 cells via STAT3 and STAT6 activation and was demonstrated to dampen inflammation [21]. The opposite actions of the CXCR3 agonists are likely the consequence of the biased signaling that is a fixture of GPCRs, which can activate both $\mathrm{G}$ protein-dependent and protein-independent signaling cascades, the latter occurring via $\beta$-arrestin 2 recruitment $[1,11,12]$. Biased allosteric agonists of CXCR3 that selectively activate $\beta$-arrestin or $\mathrm{G}$ protein-dependent signaling are in development and may have utility in immunotherapy [22].

\section{Coronary Artery Disease (Ischemic Heart Disease)}

Coronary artery disease (CAD), which progresses to coronary heart disease, is a leading cause of death in the USA and globally $[23,24]$. CAD is caused by atherosclerosis within the arteries of the heart, a chronic inflammatory condition associated with waxy plaque buildup [25]. CXCR3 expressing monocytes/macrophages, Th1 cells, NK cells, and CTL cells play a critical role in atheromatous plaque progression and eventual disruption [1]. Ruptured or ulcerated plaques cause formation of a thrombus that precipitates an acute coronary syndrome, such as unstable angina or a heart attack.

Endothelial dysfunction, increased vascular permeability, increased expression of adhesion molecules on endothelial cells for leukocytes, and increased plasma levels of low density lipoprotein (LDL) are initiating factors in atherosclerosis [1]. LDL, which accumulates in the intima, undergoes oxidation by macrophages and endothelial cells, as well as by VSMC that migrate into the intima from the media and proliferate. In response to the oxidized LDL and plasma LDL, endothelial cells secrete proinflammatory cytokines and chemokines (MCP-1/CCL2, fractalkine, and CXCR3 ligands) that attract monocytes, which differentiate into dendritic cells or macrophages that accumulate oxidized LDL to become foam cells. $T$ cells are recruited into the intima, and dendritic and NK cells help induce the $\mathrm{CD} 4^{+}$Thl phenotype, which is the most abundant $\mathrm{T}$ cell population in human atherosclerotic plaques [26]. CXCR3 is required for optimal Th1 generation [27]. Thl cells, as do NK cells, produce IFN- $\gamma$, which contributes to Th1 polarization, activates proinflammatory M1 macrophages, and induces apoptosis. The atheromatous plaque that builds up in the artery wall is made up of an accumulation of lipids, fibrous connective tissue, macrophages, and cellular debris that arises from the cytolytic actions of oxidized LDL, NK cells, IFN- $\gamma$, and CTL cells on macrophages, foam cells, VSMC, and endothelial cells. A fibrous coat of extracellular matrix proteins produced by VSMC stabilizes the plaque, but proinflammatory M1 macrophages secrete metalloproteinases in response to IFN- $\gamma$ that degrade the fibrous cap and enhance its vulnerability to rupture.

CXCL10 is reported to be expressed by endothelial cells, smooth muscle cells, and macrophages during the formation of atherosclerotic lesions in both preclinical and clinical studies $[28,29]$. Suppression of CXCL10 bioactivity in Apo$\mathrm{E}$ deficient mice resulted in a more stable plaque phenotype with less macrophage activation, along with more smooth muscle cells and collagen abundance [30]. The mechanistic role of CXCL10 in the pathogenesis of atherosclerotic plaque growth and destabilization is not yet resolved. Of note, CXCL10 concentrations increase in patients with a more vulnerable plaque phenotype [30]. Unstable plaques have increased levels of Th1, NK, and CTL cells and decreased levels of anti-inflammatory regulatory $\mathrm{T}$ (Treg) cells [31]. Recent studies show that the relative levels of Treg cells are reduced and their functionality is impaired in patients with CAD $[32,33]$. Knockout of CXCL10 in the apolipoprotein E-deficient mouse model of atherosclerosis was associated with increased Treg cell numbers and activity, along with a reduction in lesion formation [34].

Circulating levels of CXCL10 are elevated in patients with coronary artery disease $[35,36]$. Notably, CXCL10 was also reported to be produced by the endothelium of mouse coronary blood vessels infused with angiotensin II [37], human coronary artery endothelial cells treated with TNF- $\alpha$ [38], and rat cardiac microvascular endothelial cells subjected to hypoxia/ischemia [39]. Patients with acute myocardial infarction (AMI) showed significantly higher serum levels of CXCL10 than control subjects and patients with stable 
angina pectoris [40]. Although serum CXCL10 levels were negatively correlated with infarct size, these results in terms of pathogenic implications and determining cause versus effect relationships have limitations. First, during AMI there is a massive systemic inflammatory insult in which CXCL10 levels are expected to be high. It would be interesting to test blood concentration of CXCL10 within the first 3 hours after angina onset during AMI when systemic activation is not yet started. Secondly, the pathogenic mechanisms of plaque rupture may involve factors acting locally without necessarily showing a high systemic blood concentration. It would be interesting to analyze CXCL10 in samples of blood obtained by thrombus-aspiration during coronary artery percutaneous intervention (PCI) in patients with unstable coronary artery disease. In patients with first-time ST-segment elevation AMI, high circulating levels of CCL4, CXCL16, CXCL8, and CXCL10 within the first week after PCI were found to be positively correlated with the degree of myocardial damage [41].

\section{Kawasaki Disease}

Kawasaki disease is an autoimmune disease that manifests as a systemic vasculitis with a predilection for coronary arteries [42]. The disease occurs in children under 5 years of age and a preexisting viral infection may have a role in its development. During the acute phase of Kawasaki disease the immune system is highly activated and includes both Th1 and Th2 subsets [43]. Recently, Ko et al. [44] reported that CXCL10 is a good biomarker/predictor of Kawasaki disease and, furthermore, that CXCR3 is activated in the T cells of patients with acute Kawasaki disease. In addition, several studies report that numbers and functionality of Treg cells are reduced in Kawasaki patients [45-48].

\section{Myocarditis and Chagas Heart Disease}

Myocarditis or inflammation of the myocardium is a heterogeneous group of disorders initiated by various pathogens, including worms, bacteria, protozoa, rickettsia, and most commonly viruses [49]. Myocarditis may lead to heart failure and sudden death. Autoimmunity after viral myocarditis is thought to cause dilated cardiomyopathy, which is characterized by ventricular dilation and contractile dysfunction $[50,51]$.

CXCL10 is elevated in the heart following viral and nonviral infection and has the characteristics of a biomarker in rodent models of myocarditis [52, 53]. Yue et al. [54] reported findings showing that CXCL10 contributes to the pathogenesis of viral myocarditis. In their study, myocarditis was induced with Coxsackievirus B3 (CVB3), the primary cause of viral myocarditis, in mice that overexpressed a CXCL10 mutant protein without functional activity in order to antagonize endogenous CXCL10. These mice exhibited ameliorated disease progression, including reduced cardiac thickening (due to inflammatory edema), inflammation, and cell death, as well as improved survival when compared to wild-type mice [54]. The authors concluded that CXCL10 plays a crucial role in recruitment of Thl cells to the heart, leading to the increase in detrimental proinflammatory Th1 cytokines. These findings have implications for interferon treatment, which is beneficial for some forms of viral myocarditis [55]. Following CVB3 infection, the rise in IFN- $\gamma$ stimulates CXCL10 expression in cardiac myocytes and other cardiac cells. Yuan et al. [56] reported that CXCL10 inhibits CVB3 replication at early stage of infection, consequently protecting cardiac myocytes from damage and improving heart function. This antiviral activity of CXCL10 entails the regulation of natural killer (NK) cell infiltration into the myocardium and associated IFN- $\gamma$ expression. However, the transient antiviral effect of CXCL10 was shown to be insufficient for viral clearance and in preventing death during acute inflammation stages in their mouse model. Other chemokines or cytokines were proposed to play an important role in clearance of viruses. No simple explanation seems to explain the disparate findings of Yuan et al. [56] and Yue et al. [54] on whether myocardial CXCL10 is harmful or beneficial in the context of acute CVB3 myocarditis, although timing and dosage levels of CXCL10 and effective viral clearance versus Th1 recruitment are likely contributing factors.

Evidence indicates the major contribution of autoimmunity to the etiology of myocarditis and thus adoptive transfer of Tregs and/or stimulating their differentiation are promising therapeutic approaches $[49,50]$. Another possible immunotherapy approach is humanized monoclonal antibodies targeting IL-17 derived from Th17 cells [49]. Both Th1 and Th17 cells drive myocarditis, with Th17 cells playing an important part in the development of dilated cardiomyopathy [57].

Chagas disease is a tropical disease that results from infection with the protozoan parasite Trypanosoma cruzi and affects $\sim 10$ million individuals worldwide but is most prevalent in Latin America [58, 59]. In some, 20-30\%, of infected individuals, chronic infection leads to a potentially fatal cardiomyopathy known as Chagas heart disease, generally 10-20 years after the initial infection [60, 61]. Chagas heart disease is characterized by marked inflammation and fibrosis of the heart, along with cardiac edema, myofibrillar destruction, chamber dilation, and loss of contractile function. The etiology of Chagas heart disease is not fully understood and likely multifactorial, with a contribution of an autoimmune response due in part to molecular mimicry between antigenic determinants of T. cruzi and human (cardiac) antigens $[62,63]$. With heart failure in Chagas disease, myocardial levels of $\mathrm{CD}^{+}$and $\mathrm{CD} 4^{+} \mathrm{T}$ cells are increased, with a predominance of $\mathrm{CD} 8^{+} \mathrm{T}$ cells $[61,64,65]$. In addition, the myocardium exhibits a strong Thl cytokine profile with increased expression of IFN- $\gamma$ and IL-18 genes that correlate with ventricular dilation $[64,65]$. Circulating levels of IFN$\gamma$ are elevated during chronic Chagas disease [61] and were reported to be inversely correlated to left ventricular ejection fraction (LVEF) [66]. In contrast, Chagas-related heart failure is associated with reduced myocardial levels of Treg cells [61, 64], and circulating Treg activity was reported to be reduced in moderate or severe cardiomyopathy with activity directly correlated to LVEF [66].

Several studies have implicated CXCL10 in Chagas cardiomyopathy. Increased plasma levels of CXCL10 were 
detected in patients with chronic Chagas disease [67], and LV mRNA expression levels of CXCL10 were found to be elevated in patients with Chagas cardiomyopathy [68]. Recently, evidence was provided that polymorphisms in the CXCL9 and CXCL10 genes controlled the expression of chemokines in the myocardium and the degree of myocarditis in Chagas cardiomyopathy [69].

Behçet's disease is an autoimmune or autoinflammatory disorder common in the Middle East, Asia, and Japan. The basis for the pathogenesis of Behçet's disease is not known, although a number of factors have been proposed to have a role, including viral, bacterial, environmental, genetic, and immune factors. Behçet's is caused by smallvessel systemic vasculitis that very often affects the heart in diverse ways, including endomyocardial fibrosis, intracardiac thrombus, endocarditis, pericarditis, myocarditis, coronary arteritis, myocardial infarction, and valvular disease [70]. The cardiomyopathy may be ischemic, nonischemic, or inflammatory in nature and may manifest as asymptomatic systolic or diastolic dysfunction or overt systolic or diastolic heart failure [70]. Recently, monocytes of Behçet's patients were found to have dysfunctional posttranscriptional regulation of CXCL10 mRNA that resulted in overexpression of CXCL10 protein with IFN- $\gamma$ stimulation [70]. Thus, overexpression of CXCL10 may contribute to the pathogenesis of Behçet's disease. In general, the role of CXCL10 in immune-mediated and autoimmune myocarditis is little studied; however, based on studies of infective myocarditis, a critical role for CXCL10 is likely. The role of CXCL10 in cardiac allograft transplantation rejection is discussed elsewhere [1].

\section{LV Hypertrophy and Nonischemic Heart Failure}

After CAD, hypertension is the most common risk factor for heart failure and accounts for $\sim 25 \%$ of heart failure cases [71]. In the elderly, as many as $68 \%$ of heart failure cases are linked to hypertension and community-based studies indicate that hypertension contributes to heart failure in $60 \%$ of patients [72]. Hypertension causes a number of adverse remodeling events at the cellular and tissue level of the heart, including cardiac myocyte hypertrophy and gene reprograming, activation of cardiac fibroblasts, interstitial and perivascular fibrosis, and capillary refraction [73-75]. These alterations ultimately cause marked changes in the overall geometry of the heart that may progress to heart failure and the inability of the heart to adequately meet the oxygen and energy demands of the body. Heart failure (HF) may manifest clinically with either preserved or reduced LVEF, which are designated HFpEF (so-called diastolic heart failure) and HFrEF (systolic heart failure), respectively [75].

Hypertension results in concentric LV hypertrophy, which may progress to ventricular dilation and eventual HFrEF because of poorly understood means that may include ischemic injury $[76,77]$. Related to this, volume overload due to fluid retention and impaired kidney function may cause a dilated pattern of eccentric LV hypertrophy with hypertension that leads to HFrEF [77]. Generally, cardiac remodeling with hypertension reflects a combination of both concentric and eccentric patterns of remodeling [77]. Concentric hypertrophy is also a characteristic of HFpEF, which typically has hypertension as the major comorbidity [78]. In addition, microvascular dysfunction concomitant to hypertension is thought to be a contributing factor for HFpEF [79]. The relative importance of CXCL10 in concentric versus eccentric LV hypertrophy, as well as their progression to heart failure, is not known.

Numerous preclinical and clinical studies have implicated marked activation of neurohormonal drive to the heart in the pathoetiology of LV hypertrophy and its progression to heart failure [80]. Neurohormonal drive, namely, activation of the sympathetic and renin-angiotensin-aldosterone systems, is generally thought to directly cause adverse remodeling of the heart. At the same time, there is evidence for indirect actions of neurohormonal stimulation on cardiac remodeling via activation of innate immunity and inflammation, especially the induction of heart-derived proinflammatory cytokines [81]. In chronic heart failure, an increased $\mathrm{Th} 1 / \mathrm{Th} 2$ ratio is seen [82], but whether increased Thl cell levels contribute to heart failure progression or simply are a consequence of heart failure is unresolved.

Exciting new findings have now implicated adaptive immunity and $\mathrm{T}$ cells more directly as causal agents in hypertensive LV hypertrophy and resultant heart failure by poorly understood means. These preclinical studies employed the mouse model of transverse aortic constriction- (TAC-) induced heart failure to mimic the impact of high blood pressure on the heart. We observed that circulating levels of CXCL9 and CXCL10 are elevated in TAC mice [83]. Laroumanie et al. [84] reported increased recruitment of activated $\mathrm{CD}^{+}$and $\mathrm{CD} 8^{+} \mathrm{T}$ cells and elevated levels of several chemokines for $\mathrm{T}$ cells and monocytes, including CXCL10, in ventricular tissues from mice with TAC-induced heart failure. TAC-induced ventricular dilation and fibrosis was prevented and contractile dysfunction was attenuated in mice deficient in mature $\mathrm{B}$ and $\mathrm{T}$ lymphocytes due to knockout of RAG2, although cardiac hypertrophy was still observed. T cell replenishment in RAG2 knockout mice restored the TAC-induced heart failure phenotype. In addition, elimination of $\mathrm{CD}^{+} \mathrm{T}$ cells (MHCII knockout) but not $\mathrm{CD}^{+} \mathrm{T}$ cells $\left(\mathrm{CD}^{+}\right.$knockout) prevented TAC-induced cardiac fibrosis and failure, suggesting a critical involvement of $\mathrm{T}$ helper cells. This conclusion was further supported by the observation that mice with transgenic $\mathrm{T}$ cell receptor specific for ovalbumin did not develop heart failure and fibrosis with TAC. Altogether these findings suggest that activation of $\mathrm{CD}^{+} \mathrm{T}$ cells in hypertension causes interstitial and perivascular fibrosis that leads to functional and morphological changes in the heart conducive to the development of heart failure. However, it should be noted that an earlier study reported that coronary vessels of RAG1 knockout mice exhibited more intimal hyperplasia and perivascular fibrosis compared to wild-type mice following TAC [85]. The basis for the discrepant findings of the two studies is not clear. More recently, Nevers et al. [86] also investigated the role of $\mathrm{T}$ cells in cardiac remodeling in response to TAC-induced pressure overload. They observed that the development of 
systolic dysfunction was associated with the kinetics of $\mathrm{T}$ cell infiltration into the left ventricle and evidence was provided that most of the infiltrating T cells were IFN- $\gamma$ secreting Th1 cells. LV systolic and diastolic function were preserved with TAC in T cell deficient mice ( $\mathrm{T}$ cell receptor (TCR) knockout), and LV hypertrophy, fibrosis, and inflammation were markedly attenuated. In addition, $\mathrm{T}$ cell depletion with an anti-CD3 antibody prevented heart failure in wild-type mice. Unresolved at present is the identity of the antigen(s) responsible for $\mathrm{T}$ cell activation in LV hypertrophy and heart failure, and the potential contribution played by the loss of regulatory mechanisms that normally protect the heart from T cells [87].

In contrast to the involvement of adaptive immunity in TAC, Ma et al. [88] provided evidence that $\mathrm{CD}^{+} \mathrm{T}$ cells play a critical role in perivascular and interstitial fibrosis in the angiotensin II infusion model of hypertensive cardiac remodeling through the recruitment and activation of macrophages. They found that $\mathrm{CD} 8^{+} \mathrm{T}$ cells are recruited to the heart and activated by IFN- $\gamma$ secreting myocardial cells; recruited macrophages in turn are activated by $\mathrm{CD} 8^{+} \mathrm{T}$ cells in contact-dependent, but TCR-independent means. A possible contribution of $\mathrm{CD} 4^{+} \mathrm{T}$ cells to the actions of $\mathrm{CD} 8^{+}$ T cells will need to be explored.

Circulating levels of CXCL10 are elevated in patients with untreated essential hypertension [89]. In a small cohort, we observed that the CXCR3 chemokines, including CXCL10, were present in elevated concentrations in the plasma of patients with symptomatic diastolic LV dysfunction indicative of HFpEF or early stage HFrEF [90]. The magnitude of their increase was independent of the extent of hypertension and the CXCR3 agonists enhanced diagnostic accuracy over and beyond NT-pro BNP. More recently, we reported that circulating CXCL10, MIP- $1 \alpha$, and CD 40 ligand were the best indicators for differentiating healthy and heart failure subjects [91]. We found that serum CXCL10 levels were increased in patients with symptomatic heart failure as indexed by NYHA classification II through IV and were positively correlated with serum levels of Thl proinflammatory cytokines. The findings of these two studies are consistent with the idea that inflammation is involved in the pathogenesis of heart failure with CXCL10 playing a central role.

Numerous preclinical studies and recent genome-wide association studies (GWAS) support a role for both cytotoxic $\left(\mathrm{CD}^{+}\right) \mathrm{T}$ cells and $\mathrm{Th}\left(\mathrm{CD}^{+}\right)$lymphocytes in human hypertension [92, 93]. However, accumulating evidence from experimental studies indicates that increasing Treg cell levels in hypertension is an effective strategy to preserve cardiac function, attenuate cardiac hypertrophy and fibrosis, and prevent heart failure progression, independent of any blood pressure lowering effects [94-96]. Reduced circulating levels of Treg cells in heart failure patients have been reported in several studies [97-99].

The role of CXCL10 in other forms of nonischemic heart failure with reduced ejection fraction, such as restrictive cardiomyopathy, ion channelopathies, and diabetic cardiomyopathy, awaits investigation. Recently, Di Luigi et al. [100] reported that the phosphodiesterase type 5 inhibitor sildenafil decreased elevated circulating CXCL10 levels in subjects with diabetic cardiomyopathy, suggesting that sildenafil could be used pharmacologically to mitigate CXCL10associated inflammation in diabetic cardiomyopathy. Recent findings support a role for CXCL10 in right ventricular (RV) remodeling as well. Waehre et al. [101] found that several chemokines, most notably CXCL10, are upregulated in the pressure-overloaded right ventricle and play a role in myocardial extracellular matrix remodeling in an animal model of pulmonary stenosis. CXCL10 is implicated also in $\mathrm{RV}$ dysfunction and inflammation following experimental pulmonary embolism in rats [102].

\section{Implications for Immunotherapy}

The chemokine receptor CXCR3 and its agonist CXCL10 are potential drug targets to treat various cardiovascular diseases.

Potential immunotherapies for cardiac inflammation are as follows:

Treg Stimulation

(i) IL-2/anti-IL-2 complex treatment to enhance Treg number and activity

(ii) Targeted cytokine-infused nanoparticles to stabilize and expand Tregs in vivo

(iii) Intravenous immunoglobulin (IVIG) therapy to boost Treg activity

(iv) Vitamin $D$ to modulate formation and activity of Tregs

(v) Atorvastatin to enhance Treg number and activity

(vi) FTY720 to increase Treg levels and activity

(vii) Adoptive Treg cell transfer

Immunosuppression

(i) Immunoadsorption to remove circulating antibodies and boost Treg activity

(ii) Phosphodiesterase type 5 inhibitor to decrease CXCL10 formation

(iii) CXCL11 to stimulate biased GPCR anti-inflammatory signaling

(iv) PPAR- $\gamma$ agonists to block CXCL9, CXCL10, and CXCL11 formation

Levels of CXCL10 are generally elevated with chronic cardiac inflammation, which is associated with enhanced Th1 polarization and infiltration into the myocardium. CXCR3 plays a key role in recruiting various leukocytes to the heart, including monocytes, effector lymphocytes, and CTL cells [1]. Peroxisome proliferator-activated receptor- (PPAR-) $\gamma$ agonists may be a potential pharmacological treatment to block CXCL9, CXCL10, and CXCL11 formation in patients, as PPAR- $\gamma$ agonists show a strong inhibitory effect on their expression and production in vitro [103]. Pioglitazone, which lacks the adverse cardiovascular effects of older thiazolidinediones and may be cardiovascular protective, looks promising in this regard, although pioglitazone is contraindicated in 
TABLE 1: Immunological Mediators in Chronic Inflammation of the Heart.

\begin{tabular}{lccc}
\hline Disease & $\begin{array}{c}\text { Elevated } \\
\text { Th1 }\end{array}$ & $\begin{array}{c}\text { Depressed } \\
\text { Tregs }\end{array}$ & $\begin{array}{c}\text { Elevated } \\
\text { CXCL10 }\end{array}$ \\
\hline CAD & $1 ; 27 ; 31 ; 32$ & $32-34$ & $35-37$ \\
Kawasaki & 44 & 45 & $46-49$ \\
Myocarditis/Chagas & $58 ; 62 ; 65 ;$ & $62 ; 65 ; 67$ & $68 ; 69 ; 71$ \\
& 66 & & \\
Hypertrophy & $83 ; 84 ; 86 ;$ & $97-99$ & $84 ; 89-91$ \\
\hline
\end{tabular}

heart failure patients likely due to fluid retention [104107]. Another potential therapeutic approach is the phosphodiesterase type 5 inhibitor sildenafil, which was recently reported to decrease CXCL10 gene expression and protein secretion in human cardiac myocytes and decrease circulating CXCL10 in subjects with diabetic cardiomyopathy [100]. There is substantial evidence that sildenafil has protective effects against adverse remodeling of the heart [108].

Although CXCL9, CXCL10, and CXCL11 all bind to CXCR3, there is evidence that these agonists activate opposing responses due to biased signaling that is a fixture of G protein-coupled receptors [1, 11, 12]. Whereas CXCL9/ CXCL10/CXCR3 interactions drive effector Th1 polarization, CXCL11/CXCR3 binding seems to induce an immunotolerant state characterized by $\mathrm{T}$ lymphocyte polarization into regulatory $\operatorname{Tr} 1$ lymphocytes that produce anti-inflammatory IL-10 [11, 12]. Therefore, inhibiting CXCR3 may not yield definitive findings. Biased agonists have been developed that exert CXCL11-like actions at CXCR3 [22] but have not as yet been assessed in experimental models of cardiovascular diseases. An alternative approach might involve a biological compound. CXCL11 has a short half-life in vivo. To address this shortcoming, Zohar et al. [21] generated a stabilized form of CXCL11 by creating a fusion protein in which CXCL11 was linked to IgG1. When administered during ongoing autoimmune encephalomyelitis, the fusion protein suppressed the disease by increasing the number of IL-10-secreting Trl-like cells (direct effect) and reducing Th1 polarization.

Targeting CXCR3 might be more effective in treating chronic heart inflammation in combination with approaches to enhance Treg numbers or activity, which are generally reduced in cardiovascular diseases (Table 1). Regulatory $\mathrm{T}$ cells are immunosuppressive and anti-inflammatory, and a growing number of experimental studies have shown their beneficial effects on the heart in various experimental models of coronary artery disease [109, 110], Kawasaki disease [111], myocarditis and dilated cardiomyopathies [112-117], Chagas heart disease $[118,119]$, hypertensive LV hypertrophy $[95,96]$, and nonischemic heart failure [94, 109, 120]. Although not discussed here, boosting Treg numbers or activity in the heart is reported to be beneficial as well in experimental models of infarction-driven remodeling [121-124]. Increasing levels of IL-10-secreting Treg/Tr1 cells may be particularly advantageous, as IL-10 has anti-inflammatory and protective actions on the vasculature and heart [125-132]. Intravenous immunoglobulin (IVIG) therapy has been shown to be effective in treating acute Kawasaki disease in $80-90 \%$ of Kawasaki patients with rapid resolution of clinical symptoms and reduced risk of coronary disease [133]. Although the exact basis for the effectiveness of IVIG therapy is not clear, IVIG therapy is thought to modulate the inflammatory process and recent evidence indicates that IVIG therapy acts in part by stimulating an immature myeloid population of dendritic cells that secretes IL-10 and favors expansion of Fc-specific natural Treg cells [134]. IVIG may have promise for treating viral myocarditis [55] and might be effective in treating Chagas [135], as well as chronic heart failure, including both ischemic and idiopathic dilated cardiomyopathies [136].

Adoptive transfer of Tregs and/or stimulating their differentiation are promising therapeutic approaches to target cardiac inflammation $[49,50]$, although the concerns that must be overcome to make adaptive transfer routine therapy in humans are considerable [137]. However, the safety and efficacy of Treg immunotherapy in humans is supported by preliminary clinical trials for treating graft versus host disease $[137,138]$. Immunoadsorption, which is a promising approach for treating myocarditis and dilated cardiomyopathy, may have beneficial effects by not merely removing circulating antibodies, but increasing Treg activity [49, 139141].

It may be feasible to selectively enhance Treg numbers using a pharmacological approach. The prodrug FTY720 (Fingolimod) is phosphorylated in vivo and has been shown to trap naive and memory $\mathrm{T}$ cells in the thymus and secondary lymphoid organs by downregulating sphingosine 1-phosphate receptor 1 (S1P1) [142]. Activation of S1P1 is linked to inhibition of Treg cell differentiation [142]; however, FTY720 and phosphorylated FTY720 increase Treg levels and activity in vivo and in vitro [143-146]. The exact mechanism is unclear but may require higher doses [144]. The inhibitory effects of atorvastatin on inflammation in acute coronary syndrome (ACS) may be due to its beneficial effects on natural Tregs [147]. In patients with ACS, atorvastatin treatment increased the percentage and inhibitory ability of natural Tregs.

IL-2 plays a critical role in Treg cell activity, growth, and survival, but there may be insufficient IL-2 to sustain their in vivo potentiation [12]. Emerging evidence indicates that enhancing Treg cell numbers and activity with lowdose IL-2 treatment is effective in treating autoimmune and inflammatory diseases [12,148-151], although there may be intrinsic risk as IL-2 is also a key growth factor for effector $\mathrm{CD}^{+}{ }^{+} \mathrm{T}$ cells and NK cells [12]. An IL-2/anti-IL-2 immune complex is reported to preferentially expand Treg cells with little or no effect on other cells [121]. Delivery of the complex to mice before TAC was recently reported to attenuate LV hypertrophy, inflammation, and contractile dysfunction, while increasing LV levels of Treg cells [94]. Inert biodegradable nanoparticles represent another promising platform for stabilizing and expanding Tregs in vivo. McHugh et al. [152] recently reported success in using nanoparticles loaded with the Treg inducers IL-2 and TGF- $\beta$ and targeted to CD $4^{+} \mathrm{T}$ cells with conjugated antibodies. These nanoparticles were demonstrated to induce $\mathrm{CD} 4^{+}$Tregs in vitro, even in the 
presence of proinflammatory cytokines, and expand their number in mice in vivo.

Vitamin D status has been linked to chronic heart failure and vitamin D supplementation improves LV structure and function in heart failure patients [153]. Recent evidence indicates a modulatory role of the vitamin $\mathrm{D}$ system in the formation and activity of regulatory $\mathrm{T}$ cells [154]. Vitamin $\mathrm{D}$ deficiency was associated with reduced numbers and impaired function of naïve CD45RA ${ }^{+}$regulatory $\mathrm{T}$ cell in chronic heart failure patients [120]. In addition, the vitamin D receptor agonist BXL-01-0029 was shown to inhibit IFN$\gamma$ and TNF- $\alpha$-induced CXCL10 secretion by fetal human cardiac myocytes and reduce CXCL10 protein secretion and gene expression by $\mathrm{CD} 4^{+} \mathrm{T}$ cells [155]. Whether a vitamin $\mathrm{D}$ receptor agonist or supplementation increases Treg levels and reduces CXCL10 levels in heart failure patients will need to be assessed.

\section{Conclusions and Future Perspectives}

The last decade has witnessed an impressive advance in our understanding of the role of the immune system in the pathophysiology of cardiovascular diseases. Beyond an expected role in allograft disease and the development and progression of atherosclerosis, an abundant body of evidence supports a significant contribution of the immune system to many other cardiovascular settings, ranging from the development and maintenance of hypertension to cardiac and vessel remodeling (whether constrictive or expansive) in response to hemodynamic stress [156], in both health and disease. The challenge now is to translate this knowledge for the benefit of patients suffering from cardiovascular diseases. Targeting the CXCL10/CXCR3 axis and cardiac inflammation may open new pharmacological venues for treating heart failure or coronary artery disease to supplement current drugs that target the sympathetic or reninangiotensin systems, or platelets. This will require selectively targeting the most critical immune pathways in order to optimize interference with pathological processes, while preserving protective and homeostatic immune functions. Antigen-specific modulation of the immune system, for example, through systemic delivery of nanoparticles coated with disease-relevant peptides bound to major histocompatibility complex class II (pMHCII) to expand endogenous antigen-specific Tregs [157], is an optimal strategy in settings where an antigen-specific adaptive immune response has been involved in disease development or progression. However, several cardiovascular diseases will probably resist the identification of a specific pathogenic antigen and will require a broader, although targeted, regulation of the immune response, for example, through administration of low-dose IL-2 to promote endogenous Tregs [149]. With regard to CXCR3 pathway, besides the therapeutic possibilities listed above, we believe that the identification and development of selective Evasins [158] or Evasin-like peptides that differentially bind and neutralize CXCL9 or CXCL10 versus CXCL11 may provide an interesting therapeutic strategy to limit pathogenic while preserving regulatory CXCR3 functions.

\section{Competing Interests}

The authors have no competing interests to declare.

\section{Acknowledgments}

The authors are very appreciative of the thoughtful suggestions and comments of Drs. Abdullah Kaplan and Rana Ghali El-Ghoul in the preparation of this manuscript. The authors would like to acknowledge the generous support of the Department of Pharmacology and Toxicology of the University of Mississippi Medical Center (Raffaele Altara, George W. Booz). This work was supported by a grant (100410) from the American University of Beirut to Fouad A. Zouein. Ziad Mallat is supported by the European Research Council and the British Heart Foundation.

\section{References}

[1] R. Altara, M. Manca, R. D. Brandao, A. Zeidan, G. W. Booz, and F. A. Zouein, "Emerging importance of chemokine receptor CXCR3 and its ligands in cardiovascular diseases," Clinical Science, vol. 130, no. 7, pp. 463-478, 2016.

[2] P. van den Borne, P. H. A. Quax, I. E. Hoefer, and G. Pasterkamp, "The multifaceted functions of CXCL10 in cardiovascular disease," BioMed Research International, vol. 2014, Article ID 893106, 11 pages, 2014.

[3] K. Van Raemdonck, P. E. Van den Steen, S. Liekens, J. Van Damme, and S. Struyf, "CXCR3 ligands in disease and therapy," Cytokine and Growth Factor Reviews, vol. 26, no. 3, pp. 311-327, 2015.

[4] A. Kouroumalis, R. J. Nibbs, H. Aptel, K. L. Wright, G. Kolios, and S. G. Ward, "The chemokines CXCL9, CXCL10, and CXCL11 differentially stimulate $\mathrm{G} \alpha \mathrm{i}$-independent signaling and actin responses in human intestinal myofibroblasts," The Journal of Immunology, vol. 175, no. 8, pp. 5403-5411, 2005.

[5] M. Svensson, K. Russell, M. Mack, and K. J. Else, "CD4 $4^{+}$Tcell localization to the large intestinal mucosa during Trichuris murisinfection is mediated by $\mathrm{G} \alpha_{\mathrm{i}}$-coupled receptors but is CCR6- and CXCR3-independent," Immunology, vol. 129, no. 2, pp. 257-267, 2010.

[6] B. D. Thompson, Y. Jin, K. H. Wu et al., "Inhibition of G $\alpha \mathrm{i} 2$ activation by G $\alpha$ i3 in CXCR3-mediated signaling," Journal of Biological Chemistry, vol. 282, no. 13, pp. 9547-9555, 2007.

[7] A. Korniejewska, A. J. Mcknight, Z. Johnson, M. L. Watson, and S. G. Ward, "Expression and agonist responsiveness of CXCR3 variants in human T lymphocytes," Immunology, vol. 132, no. 4, pp. 503-515, 2011.

[8] A. Mueller, A. Meiser, E. M. McDonagh et al., "CXCL4-induced migration of activated $\mathrm{T}$ lymphocytes is mediated by the chemokine receptor CXCR3," Journal of Leukocyte Biology, vol. 83, no. 4, pp. 875-882, 2008.

[9] P. von Hundelshausen and M. M. N. Schmitt, "Platelets and their chemokines in atherosclerosis-clinical applications," Frontiers in Physiology, vol. 5, article 294, 2014.

[10] X. Blanchet, K. Cesarek, J. Brandt et al., "Inflammatory role and prognostic value of platelet chemokines in acute coronary syndrome," Thrombosis and Haemostasis, vol. 112, no. 6, pp. 1277-1287, 2014.

[11] N. Karin, G. Wildbaum, and M. Thelen, "Biased signaling pathways via CXCR3 control the development and function of 
CD $4^{+}$T cell subsets," Journal of Leukocyte Biology, vol. 99, no. 6, pp. 857-862, 2016.

[12] N. Karin and G. Wildbaum, "The role of chemokines in adjusting the balance between CD4+ effector T cell subsets and FOXp3-negative regulatory T cells," International Immunopharmacology, vol. 28, no. 2, pp. 829-835, 2015.

[13] P. Fallahi, S. M. Ferrari, G. Elia et al., "Novel therapies for thyroid autoimmune diseases," Expert Review of Clinical Pharmacology, vol. 9, no. 6, pp. 853-861, 2016.

[14] C. Billottet, C. Quemener, and A. Bikfalvi, "CXCR3, a doubleedged sword in tumor progression and angiogenesis," Biochimica et Biophysica Acta-Reviews on Cancer, vol. 1836, no. 2, pp. 287-295, 2013.

[15] A. K. Azad, W. Sadee, and L. S. Schlesinger, "Innate immune gene polymorphisms in tuberculosis," Infection and Immunity, vol. 80, no. 10, pp. 3343-3359, 2012.

[16] M. Liu, S. Guo, J. M. Hibbert et al., "CXCL10/IP-10 in infectious diseases pathogenesis and potential therapeutic implications," Cytokine and Growth Factor Reviews, vol. 22, no. 3, pp. 121-130, 2011.

[17] R. S. Klein, "Regulation of neuroinflammation: the role of CXCL10 in lymphocyte infiltration during autoimmune encephalomyelitis," Journal of Cellular Biochemistry, vol. 92, no. 2, pp. 213-222, 2004.

[18] A. Antonelli, S. M. Ferrari, A. Corrado, E. Ferrannini, and P. Fallahi, "CXCR3, CXCL10 and type 1 diabetes," Cytokine and Growth Factor Reviews, vol. 25, no. 1, pp. 57-65, 2014.

[19] I. Komarowska, D. Coe, G. Wang et al., "Hepatocyte growth factor receptor c-met instructs $\mathrm{T}$ cell cardiotropism and promotes T cell migration to the heart via autocrine chemokine release," Immunity, vol. 42, no. 6, pp. 1087-1099, 2015.

[20] H. Fu, E. J. Ward, and F. M. Marelli-Berg, "Mechanisms of T cell organotropism," Cellular and Molecular Life Sciences, vol. 73, no. 16, pp. 3009-3033, 2016.

[21] Y. Zohar, G. Wildbaum, R. Novak et al., "CXCL11-dependent induction of FOXP3-negative regulatory $\mathrm{T}$ cells suppresses autoimmune encephalomyelitis," The Journal of Clinical Investigation, vol. 124, no. 5, pp. 2009-2022, 2014.

[22] L. Milanos, R. Brox, T. Frank et al., "Discovery and characterization of biased allosteric agonists of the chemokine receptor CXCR3," Journal of Medicinal Chemistry, vol. 59, no. 5, pp. 22222243, 2016.

[23] D. Mozaffarian, E. J. Benjamin, A. S. Go et al., "Heart disease and stroke statistics-2016 update: a report from the American Heart Association," Circulation, vol. 133, no. 4, pp. e38-e60, 2016.

[24] C. J. L. Murray, R. M. Barber, K. J. Foreman et al., "Global, regional, and national disability-adjusted life years (DALYs) for 306 diseases and injuries and healthy life expectancy (HALE) for 188 countries, 1990-2013: quantifying the epidemiological transition," The Lancet, vol. 386, no. 10009, pp. 2145-2191, 2015.

[25] P. Libby and P. Theroux, "Pathophysiology of coronary artery disease," Circulation, vol. 111, no. 25, pp. 3481-3488, 2005.

[26] E. Ammirati, F. Moroni, M. Magnoni, and P. G. Camici, "The role of $\mathrm{T}$ and $\mathrm{B}$ cells in human atherosclerosis and atherothrombosis," Clinical and Experimental Immunology, vol. 179, no. 2, pp. 173-187, 2015.

[27] J. R. Groom, J. Richmond, T. T. Murooka et al., "CXCR3 chemokine receptor-ligand interactions in the lymph node optimize $\mathrm{CD}^{+} \mathrm{T}$ helper 1 cell differentiation," Immunity, vol. 37, no. 6, pp. 1091-1103, 2012.
[28] F. Mach, A. Sauty, A. S. Iarossi et al., "Differential expression of three T lymphocyte-activating CXC chemokines by human atheroma-associated cells," The Journal of Clinical Investigation, vol. 104, no. 8, pp. 1041-1050, 1999.

[29] C. Cheng, D. Tempel, R. van Haperen et al., "Shear stressinduced changes in atherosclerotic plaque composition are modulated by chemokines," The Journal of Clinical Investigation, vol. 117, no. 3, pp. 616-626, 2007.

[30] D. Segers, J. A. Lipton, P. J. Leenen et al., "Atherosclerotic plaque stability is affected by the chemokine CXCL10 in both mice and humans," International Journal of Inflammation, vol. 2011, Article ID 936109, 9 pages, 2011.

[31] I. Rohm, Y. Atiskova, S. Drobnik et al., "Decreased regulatory $T$ cells in vulnerable atherosclerotic lesions: imbalance between pro- and anti-inflammatory cells in atherosclerosis," Mediators of Inflammation, vol. 2015, Article ID 364710, 13 pages, 2015.

[32] T. Emoto, N. Sasaki, T. Yamashita et al., "Regulatory/effector T-cell ratio is reduced in coronary artery disease," Circulation Journal, vol. 78, no. 12, pp. 2935-2941, 2014.

[33] L. Hasib, A. K. Lundberg, H. Zachrisson, J. Ernerudh, and L. Jonasson, "Functional and homeostatic defects of regulatory $\mathrm{T}$ cells in patients with coronary artery disease," Journal of Internal Medicine, vol. 279, no. 1, pp. 63-77, 2016.

[34] E. A. Heller, E. Liu, A. M. Tager et al., "Chemokine CXCL10 promotes atherogenesis by modulating the local balance of effector and regulatory T cells," Circulation, vol. 113, no. 19, pp. 2301-2312, 2006.

[35] T. Niki, T. Soeki, K. Yamaguchi et al., "Elevated concentration of interferon-inducible protein of $10 \mathrm{kD}$ (IP-10) is associated with coronary atherosclerosis," International Heart Journal, vol. 56, no. 3, pp. 269-272, 2015.

[36] A. Safa, H. R. Rashidinejad, M. Khalili et al., "Higher circulating levels of chemokines CXCL10, CCL20 and CCL22 in patients with ischemic heart disease," Cytokine, vol. 83, pp. 147-157, 2016.

[37] J. B. Xia, G. H. Liu, Z. Y. Chen et al., "Hypoxia/ischemia promotes CXCL10 expression in cardiac microvascular endothelial cells by NFkB activation," Cytokine, vol. 81, pp. 63-70, 2016.

[38] H. N. Qiu, B. Liu, W. Liu, and S. Liu, "Interleukin-27 enhances TNF-alpha-mediated activation of human coronary artery endothelial cells," Molecular and Cellular Biochemistry, vol. 411, pp. 1-10, 2016.

[39] N. Ide, T. Hirase, A. Nishimoto-Hazuku, Y. Ikeda, and K. Node, "Angiotensin II increases expression of IP-10 and the reninangiotensin system in endothelial cells," Hypertension Research, vol. 31, no. 6, pp. 1257-1267, 2008.

[40] K. Koten, S. Hirohata, T. Miyoshi et al., "Serum interferongamma-inducible protein 10 level was increased in myocardial infarction patients, and negatively correlated with infarct size," Clinical Biochemistry, vol. 41, no. 1-2, pp. 30-37, 2008.

[41] S. Ørn, U. M. Breland, T. E. Mollnes et al., "The chemokine network in relation to infarct size and left ventricular remodeling following acute myocardial infarction," American Journal of Cardiology, vol. 104, no. 9, pp. 1179-1183, 2009.

[42] J. W. Newburger, M. Takahashi, and J. C. Burns, "Kawasaki disease," Journal of the American College of Cardiology, vol. 67, no. 14, pp. 1738-1749, 2016.

[43] S. B. Lee, Y. H. Kim, M. C. Hyun, Y. H. Kim, H. S. Kim, and Y. H. Lee, "T-helper cytokine profiles in patients with Kawasaki disease," Korean Circulation Journal, vol. 45, no. 6, pp. 516-521, 2015. 
[44] T.-M. Ko, H.-C. Kuo, J.-S. Chang et al., "CXCL10/IP-10 is a biomarker and mediator for Kawasaki disease," Circulation Research, vol. 116, no. 5, pp. 876-883, 2015.

[45] F.-F. Ni, C.-R. Li, Q. Li, Y. Xia, G.-B. Wang, and J. Yang, "Regulatory $\mathrm{T}$ cell microRNA expression changes in children with acute Kawasaki disease," Clinical and Experimental Immunology, vol. 178, no. 2, pp. 384-393, 2014.

[46] Y. Hirabayashi, Y. Takahashi, Y. Xu et al., "Lack of $\mathrm{CD} 4^{+} \mathrm{CD} 25^{+} \mathrm{FOXP}^{+}$regulatory $\mathrm{T}$ cells is associated with resistance to intravenous immunoglobulin therapy in patients with Kawasaki disease," European Journal of Pediatrics, vol. 172, no. 6, pp. 833-837, 2013.

[47] S. Jia, C. Li, G. Wang, J. Yang, and Y. Zu, "The T helper type 17/regulatory $\mathrm{T}$ cell imbalance in patients with acute Kawasaki disease," Clinical and Experimental Immunology, vol. 162, no. 1, pp. 131-137, 2010.

[48] K. Furuno, T. Yuge, K. Kusuhara et al., " $\mathrm{CD} 25^{+} \mathrm{CD} 4^{+}$regulatory $\mathrm{T}$ cells in patients with Kawasaki disease," The Journal of Pediatrics, vol. 145, no. 3, pp. 385-390, 2004.

[49] L. D. Jensen and D. J. Marchant, "Emerging pharmacologic targets and treatments for myocarditis," Pharmacology \& Therapeutics, vol. 161, pp. 40-51, 2016.

[50] X. Meng, J. Yang, M. Dong et al., "Regulatory T cells in cardiovascular diseases," Nature Reviews Cardiology, vol. 13, no. 3, pp. 167-179, 2016.

[51] N. R. Rose, "Viral myocarditis," Current Opinion in Rheumatology, vol. 28, no. 4, pp. 383-389, 2016.

[52] S. Omura, E. Kawai, F. Sato et al., "Bioinformatics multivariate analysis determined a set of phase-specific biomarker candidates in a novel mouse model for viral myocarditis," Circulation: Cardiovascular Genetics, vol. 7, no. 4, pp. 444-454, 2014.

[53] J. L. Hardison, R. A. Wrightsman, P. M. Carpenter, T. E. Lane, and J. E. Manning, "The chemokines CXCL9 and CXCL10 promote a protective immune response but do not contribute to cardiac inflammation following infection with Trypanosoma cruzi," Infection and Immunity, vol. 74, no. 1, pp. 125-134, 2006.

[54] Y. Yue, J. Gui, W. Ai, W. Xu, and S. Xiong, "Direct gene transfer with IP-10 mutant ameliorates mouse CVB3-induced myocarditis by blunting Th1 immune responses," PLOS ONE, vol. 6, no. 3, Article ID e18186, 2011.

[55] B. Maisch and S. Pankuweit, "Standard and etiology-directed evidence-based therapies in myocarditis: state of the art and future perspectives," Heart Failure Reviews, vol. 18, no. 6, pp. 761-795, 2013.

[56] J. Yuan, Z. Liu, T. Lim et al., "CXCL10 inhibits viral replication through recruitment of natural killer cells in coxsackievirus B3Induced myocarditis," Circulation Research, vol. 104, no. 5, pp. 628-638, 2009.

[57] J. G. Barin and D. Čiháková, "Control of inflammatory heart disease by $\mathrm{CD}^{+}{ }^{+} \mathrm{T}$ cells," Annals of the New York Academy of Sciences, vol. 1285, no. 1, pp. 80-96, 2013.

[58] "Chagas disease in Latin America: an epidemiological update based on 2010 estimates," The Weekly Epidemiological Record, vol. 90, no. 6, pp. 33-43, 2015.

[59] A. Rassi Jr., A. Rassi, and J. A. Marin-Neto, "Chagas disease," The Lancet, vol. 375, no. 9723, pp. 1388-1402, 2010.

[60] L. H. Malik, G. D. Singh, and E. A. Amsterdam, "Chagas heart disease: an update," The American Journal of Medicine, vol. 128, no. 11, pp. 1251.e7-1251.e9, 2015.

[61] R. J. Argüello, C. Vigliano, P. Cabeza-Meckert et al., "Presence of antigen-experienced $\mathrm{T}$ cells with low grade of differentiation and proliferative potential in chronic Chagas disease myocarditis," PLoS Neglected Tropical Diseases, vol. 8, no. 8, Article ID e2989, 2014.

[62] E. S. Saba, L. Gueyffier, M.-L. Dichtel-Danjoy et al., "AntiTrypanosoma cruzi cross-reactive antibodies detected at high rate in non-exposed individuals living in non-endemic regions: seroprevalence and association to other viral serologies," PLoS ONE, vol. 8, no. 9, Article ID e74493, 2013.

[63] M. Alsamara and R. Alharethi, "Heart failure with preserved ejection fraction," Expert Review of Cardiovascular Therapy, vol. 12, no. 6, pp. 743-750, 2014.

[64] L. G. Nogueira, R. H. Santos, A. I. Fiorelli et al., "Myocardial gene expression of T-bet, GATA-3, Ror- $\gamma \mathrm{t}$, FoxP3, and hallmark cytokines in chronic chagas disease cardiomyopathy: an essentially unopposed $\mathrm{T}_{H}$ 1-type response," Mediators of Inflammation, vol. 2014, Article ID 914326, 9 pages, 2014.

[65] D. B. R. Rodrigues, M. A. dos Reis, A. Romano et al., "In situ expression of regulatory cytokines by heart inflammatory cells in Chagas' disease patients with heart failure," Clinical and Developmental Immunology, vol. 2012, Article ID 361730, 7 pages, 2012.

[66] P. M. M. Guedes, F. R. S. Gutierrez, G. K. Silva et al., "Deficient regulatory $\mathrm{T}$ cell activity and low frequency of IL-17-producing $T$ cells correlate with the extent of cardiomyopathy in human Chagas' disease," PLoS Neglected Tropical Diseases, vol. 6, no. 4, Article ID e1630, 2012.

[67] P. R. Luz, T. P. Velavan, P. G. Kremsner, and I. J. T. MessiasReason, "Association of IP-10 and PDGF-BB levels with clinical forms of chronic Chagas disease," International Journal of Cardiology, vol. 169, no. 4, pp. e53-e55, 2013.

[68] E. Cunha-Neto, V. J. Dzau, P. D. Allen et al., "Cardiac gene expression profiling provides evidence for cytokinopathy as a molecular mechanism in Chagas' disease cardiomyopathy," The American Journal of Pathology, vol. 167, no. 2, pp. 305-313, 2005.

[69] L. G. Nogueira, R. H. B. Santos, B. M. Ianni et al., "Myocardial chemokine expression and intensity of myocarditis in Chagas cardiomyopathy are controlled by polymorphisms in CXCL9 and CXCL10," PLoS Neglected Tropical Diseases, vol. 6, no. 10, Article ID e1867, 2012.

[70] N. Ambrose, E. Khan, R. Ravindran et al., "The exaggerated inflammatory response in Behçet's syndrome: identification of dysfunctional post-transcriptional regulation of the IFN$\gamma /$ CXCL10 IP-10 pathway," Clinical and Experimental Immunology, vol. 181, no. 3, pp. 427-433, 2015.

[71] W. B. Kannel and J. Cobb, "Left ventricular hypertrophy and mortality-results from the Framingham Study," Cardiology, vol. 81, no. 4-5, pp. 291-298, 1992.

[72] N. Yamasaki, H. Kitaoka, Y. Matsumura, T. Furuno, M. Nishinaga, and Y. Doi, "Heart failure in the elderly," Internal Medicine, vol. 42, no. 5, pp. 383-388, 2003.

[73] M. Kurdi and G. W. Booz, "Three 4-letter words of hypertension-related cardiac hypertrophy: TRPC, mTOR, and HDAC," Journal of Molecular and Cellular Cardiology, vol. 50, no. 6, pp. 964-971, 2011.

[74] G. W. Booz, "Putting the brakes on cardiac hypertrophy: exploiting the NO-cGMP counter-regulatory system," Hypertension, vol. 45, no. 3, pp. 341-346, 2005.

[75] M. H. Drazner, “The progression of hypertensive heart disease," Circulation, vol. 123, no. 3, pp. 327-334, 2011.

[76] K. Berenji, M. H. Drazner, B. A. Rothermel, and J. A. Hill, "Does load-induced ventricular hypertrophy progress to systolic heart 
failure?" American Journal of Physiology-Heart and Circulatory Physiology, vol. 289, no. 1, pp. H8-H16, 2005.

[77] S. Garg and M. H. Drazner, "Refining the classification of left ventricular hypertrophy to provide new insights into the progression from hypertension to heart failure," Current Opinion in Cardiology, vol. 31, no. 4, pp. 387-393, 2016.

[78] A. M. Katz and E. L. Rolett, "Heart failure: when form fails to follow function," European Heart Journal, vol. 37, no. 5, pp. 449454, 2016.

[79] G. Giamouzis, E. B. Schelbert, and J. Butler, "Growing evidence linking microvascular dysfunction with heart failure with preserved ejection fraction," Journal of the American Heart Association, vol. 5, no. 2, Article ID e003259, 2016.

[80] G. S. Francis, "Neurohormonal control of heart failure," Cleveland Clinic Journal of Medicine, vol. 78, no. 1, pp. S75-S79, 2011.

[81] D. L. Mann, "Innate immunity and the failing heart: the cytokine hypothesis revisited," Circulation Research, vol. 116, no. 7, pp. 1254-1268, 2015.

[82] X. Cheng, Y. Ding, C. Xia et al., "Atorvastatin modulates $\mathrm{Th} 1 / \mathrm{Th} 2$ response in patients with chronic heart failure," Journal of Cardiac Failure, vol. 15, no. 2, pp. 158-162, 2009.

[83] R. Altara, M. Manca, M. H. M. Hessel et al., "Improving membrane based multiplex immunoassays for semi-quantitative detection of multiple cytokines in a single sample," $B M C$ Biotechnology, vol. 14, article 63, 2014.

[84] F. Laroumanie, V. Douin-Echinard, J. Pozzo et al., " $\mathrm{CD} 4{ }^{+} \mathrm{T}$ cells promote the transition from hypertrophy to heart failure during chronic pressure overload," Circulation, vol. 129, no. 21, pp. 21112124, 2014.

[85] F. Yang, A. Dong, P. Mueller et al., "Coronary artery remodeling in a model of left ventricular pressure overload is influenced by platelets and inflammatory cells," PLOS ONE, vol. 7, no. 8, Article ID e40196, 2012.

[86] T. Nevers, A. M. Salvador, A. Grodecki-Pena et al., "Left ventricular t-cell recruitment contributes to the pathogenesis of heart failure," Circulation: Heart Failure, vol. 8, no. 4, pp. 776787, 2015.

[87] A. H. Lichtman, "The heart of the matter: protection of the myocardium from T cells," Journal of Autoimmunity, vol. 45, pp. 90-96, 2013.

[88] F. Ma, J. Feng, C. Zhang et al., "The requirement of CD8 ${ }^{+}$T cells to initiate and augment acute cardiac inflammatory response to high blood pressure," Journal of Immunology, vol. 192, no. 7, pp. 3365-3373, 2014

[89] A. Antonelli, P. Fallahi, S. M. Ferrari et al., "High serum levels of CXC (CXCL10) and CC (CCL2) chemokines in untreated essential hypertension," International Journal of Immunopathology and Pharmacology, vol. 25, no. 2, pp. 387-395, 2012.

[90] R. Altara, Y.-M. Gu, H. A. J. Struijker-Boudier, L. Thijs, J. A. Staessen, and W. M. Blankesteijn, "Left ventricular dysfunction and CXCR3 ligands in hypertension: from animal experiments to a population-based pilot study," PLoS ONE, vol. 10, no. 10, Article ID e0141394, 2015.

[91] R. Altara, M. Manca, M. H. Hessel et al., "CXCL10 is a circulating inflammatory marker in patients with advanced heart failure: a pilot study," Journal of Cardiovascular Translational Research, vol. 9, no. 4, pp. 302-314, 2016.

[92] J. Zhang and S. D. Crowley, "Role of T lymphocytes in hypertension," Current Opinion in Pharmacology, vol. 21, pp. 14-19, 2015.
[93] J. M. Abais-Battad, N. P. Rudemiller, and D. L. Mattson, "Hypertension and immunity: mechanisms of T cell activation and pathways of hypertension," Current Opinion in Nephrology and Hypertension, vol. 24, no. 5, pp. 470-474, 2015.

[94] H. Wang, L. Hou, D. Kwak et al., "Increasing regulatory T Cells with interleukin-2 and interleukin-2 antibody complexes attenuates lung inflammation and heart failure progression," Hypertension, vol. 68, no. 1, pp. 114-122, 2016.

[95] P. Kanellakis, T. N. Dinh, A. Agrotis, and A. Bobik, "CD $4^{+} \mathrm{CD} 25^{+} \mathrm{Foxp}^{+}$regulatory $\mathrm{T}$ cells suppress cardiac fibrosis in the hypertensive heart," Journal of Hypertension, vol. 29, no. 9, pp. 1820-1828, 2011.

[96] H. Kvakan, M. Kleinewietfeld, F. Qadri et al., "Regulatory T cells ameliorate angiotensin II-induced cardiac damage," Circulation, vol. 119, no. 22, pp. 2904-2912, 2009.

[97] N. Okamoto, T. Noma, Y. Ishihara et al., "Prognostic value of circulating regulatory $\mathrm{T}$ cells for worsening heart failure in heart failure patients with reduced ejection fraction," International Heart Journal, vol. 55, no. 3, pp. 271-277, 2014.

[98] N. Li, H. Bian, J. Zhang, X. Li, X. Ji, and Y. Zhang, "The Th17/Treg imbalance exists in patients with heart failure with normal ejection fraction and heart failure with reduced ejection fraction," Clinica Chimica Acta, vol. 411, no. 23-24, pp. 19631968, 2010.

[99] T. T. Tang, Y. J. Ding, Y. H. Liao et al., "Defective circulating CD4CD25+Foxp3+CD127(low) regulatory T-cells in patients with chronic heart failure," Cellular Physiology and Biochemistry, vol. 25, pp. 451-458, 2010.

[100] L. Di Luigi, C. Corinaldesi, M. Colletti et al., "Phosphodiesterase type 5 inhibitor sildenafil decreases the proinflammatory chemokine CXCL10 in human cardiomyocytes and in subjects with diabetic cardiomyopathy," Inflammation, vol. 39, no. 3, pp. 1238-1252, 2016.

[101] A. Waehre, M. Vistnes, I. Sjaastad et al., "Chemokines regulate small leucine-rich proteoglycans in the extracellular matrix of the pressure-overloaded right ventricle," Journal of Applied Physiology, vol. 112, no. 8, pp. 1372-1382, 2012.

[102] J. A. Watts, M. A. Gellar, M. Obraztsova, J. A. Kline, and J. Zagorski, "Role of inflammation in right ventricular damage and repair following experimental pulmonary embolism in rats," International Journal of Experimental Pathology, vol. 89, no. 5, pp. 389-399, 2008.

[103] S. M. Ferrari, A. Antonelli, A. Di Domenicantonio, A. Manfredi, C. Ferri, and P. Fallahi, "Modulatory effects of peroxisome proliferator-activated receptor- $\gamma$ on CXCR3 chemokines," Recent Patents on Inflammation and Allergy Drug Discovery, vol. 8, no. 2, pp. 132-138, 2014.

[104] E. Standl, O. Schnell, and D. K. McGuire, "Heart Failure Considerations of Antihyperglycemic Medications for Type 2 Diabetes," Circulation Research, vol. 118, no. 11, pp. 1830-1843, 2016.

[105] D. Mendes, C. Alves, and F. Batel-Marques, "Number needed to harm in the post-marketing safety evaluation: results for rosiglitazone and pioglitazone," Pharmacoepidemiology and Drug Safety, vol. 24, no. 12, pp. 1259-1270, 2015.

[106] E. Erdmann and R. Wilcox, "Pioglitazone and mechanisms of CV protection," Quarterly Journal of Medicine, vol. 103, no. 4, pp. 213-228, 2009.

[107] R. W. Nesto, D. Bell, R. O. Bonow et al., "Thiazolidinedione use, fluid retention, and congestive heart failure: a consensus statement from the American Heart Association and American 
Diabetes Association," Circulation, vol. 108, no. 23, pp. 29412948, 2003.

[108] A. Das, D. Durrant, F. N. Salloum, L. Xi, and R. C. Kukreja, "PDE5 inhibitors as therapeutics for heart disease, diabetes and cancer," Pharmacology and Therapeutics, vol. 147, pp. 12-21, 2015.

[109] G. Wang, R. Y. Kim, I. Imhof et al., "The immunosuppressant FTY720 prolongs survival in a mouse model of diet-induced coronary atherosclerosis and myocardial infarction," Journal of Cardiovascular Pharmacology, vol. 63, no. 2, pp. 132-143, 2014.

[110] K. Matrougui, Z. Abd Elmageed, M. Kassan et al., "Natural regulatory $\mathrm{T}$ cells control coronary arteriolar endothelial dysfunction in hypertensive mice," The American Journal of Pathology, vol. 178, pp. 434-441, 2011.

[111] M.-P. Chu, D. Wang, Y.-Y. Zhang et al., "Pachyman treatment improves CD4+CD25+ Treg counts and serum interleukin 4 and interferon $\gamma$ levels in a mouse model of Kawasaki disease," Molecular Medicine Reports, vol. 5, no. 5, pp. 1237-1240, 2012.

[112] R. Martín, C. Cordova, J. A. San Román, B. Gutierrez, V. Cachofeiro, and M. L. Nieto, "Oleanolic acid modulates the immune-inflammatory response in mice with experimental autoimmune myocarditis and protects from cardiac injury. Therapeutic implications for the human disease," Journal of Molecular and Cellular Cardiology, vol. 72, pp. 250-262, 2014.

[113] Y. Cao, W. Xu, and S. Xiong, "Adoptive transfer of regulatory $\mathrm{T}$ cells protects against coxsackievirus B3-induced cardiac fibrosis," PLoS ONE, vol. 8, no. 9, Article ID e74955, 2013.

[114] Y. Shi, M. Fukuoka, G. Li et al., "Regulatory T cells protect mice against coxsackievirus-induced myocarditis through the transforming growth factor $\beta$-coxsackie-adenovirus receptor pathway," Circulation, vol. 121, no. 24, pp. 2624-2634, 2010.

[115] M. Ono, J. Shimizu, Y. Miyachi, and S. Sakaguchi, "Control of autoimmune myocarditis and multiorgan inflammation by glucocorticoid-induced TNF receptor family-related protein $^{\text {high }}$, Foxp3-expressing $\mathrm{CD} 25^{+}$and $\mathrm{CD} 25^{-}$regulatory $\mathrm{T}$ cells," The Journal of Immunology, vol. 176, no. 8, pp. 4748-4756, 2006.

[116] J.-H. Lee, T.-H. Kim, H. E. Park et al., "Myosin-primed tolerogenic dendritic cells ameliorate experimental autoimmune myocarditis," Cardiovascular Research, vol. 101, no. 2, pp. 203210, 2014.

[117] G. Fousteri, A. Dave, B. Morin, S. Omid, M. Croft, and M. G. von Herrath, "Nasal cardiac myosin peptide treatment and OX40 blockade protect mice from acute and chronic virally-induced myocarditis," Journal of Autoimmunity, vol. 36, no. 3-4, pp. 210220, 2011.

[118] J. F. Vasconcelos, B. S. F. Souza, T. F. S. Lins et al., "Administration of granulocyte colony-stimulating factor induces immunomodulation, recruitment of T regulatory cells, reduction of myocarditis and decrease of parasite load in a mouse model of chronic Chagas disease cardiomyopathy," The FASEB Journal, vol. 27, no. 12, pp. 4691-4702, 2013.

[119] F. B. González, S. R. Villar, R. Fernández Bussy et al., "Immunoendocrine dysbalance during uncontrolled T. cruzi infection is associated with the acquisition of a Th-1-like phenotype by Foxp $3^{+}$T cells," Brain, Behavior, and Immunity, vol. 45, pp. 219232, 2015.

[120] Y.-H. Ma, Y.-L. Zhou, C.-Y. Yue et al., "Vitamin D deficiency contributes to the reduction and impaired function of naive $\mathrm{CD}_{45 \mathrm{RA}^{+}}$regulatory T cell in chronic heart failure," Journal of Immunology Research, vol. 2015, Article ID 547697, 18 pages, 2015.
[121] Z. Zeng, K. Yu, L. Chen, W. Li, H. Xiao, and Z. Huang, "Interleukin-2/anti-interleukin-2 immune complex attenuates cardiac remodeling after myocardial infarction through expansion of regulatory T cells," Journal of Immunology Research, vol. 2016, Article ID 8493767, 13 pages, 2016.

[122] J. Weirather, U. D. W. Hofmann, N. Beyersdorf et al., "Foxp3 ${ }^{+}$ $\mathrm{CD}^{+} \mathrm{T}$ cells improve healing after myocardial infarction by modulating monocyte/macrophage differentiation," Circulation Research, vol. 115, no. 1, pp. 55-67, 2014.

[123] T.-T. Tang, J. Yuan, Z.-F. Zhu et al., "Regulatory T cells ameliorate cardiac remodeling after myocardial infarction," Basic Research in Cardiology, vol. 107, no. 1, article 232, 2012.

[124] K. Matsumoto, M. Ogawa, J.-I. Suzuki, Y. Hirata, R. Nagai, and M. Isobe, "Regulatory T lymphocytes attenuate myocardial infarction-induced ventricular remodeling in mice," International Heart Journal, vol. 52, no. 6, pp. 382-387, 2011.

[125] G. Sikka, K. L. Miller, J. Steppan et al., "Interleukin 10 knockout frail mice develop cardiac and vascular dysfunction with increased age," Experimental Gerontology, vol. 48, no. 2, pp. 128135, 2013.

[126] Z. P. Cai, N. Parajuli, X. Zheng, and L. Becker, "Remote ischemic preconditioning confers late protection against myocardial ischemia-reperfusion injury in mice by upregulating interleukin-10," Basic Research in Cardiology, vol. 107, no. 4, article 277, 2012.

[127] M. C. Manukyan, C. H. Alvernaz, J. A. Poynter et al., "Interleukin-10 protects the ischemic heart from reperfusion injury via the STAT3 pathway," Surgery, vol. 150, no. 2, pp. 231239, 2011.

[128] N. Khaper, S. Bryan, S. Dhingra et al., "Targeting the vicious inflammation-oxidative stress cycle for the management of heart failure," Antioxidants and Redox Signaling, vol. 13, no. 7, pp. 1033-1049, 2010.

[129] M. L. Batista Jr., R. D. Lopes, M. C. L. Seelaender, and A. C. Lopes, "Anti-inflammatory effect of physical training in heart failure: role of TNF- $\alpha$ and IL-10," Arquivos Brasileiros de Cardiologia, vol. 93, no. 6, pp. 643-700, 2009.

[130] S. P. Didion, D. A. Kinzenbaw, L. I. Schrader, Y. Chu, and F. M. Faraci, "Endogenous interleukin-10 inhibits angiotensin IIinduced vascular dysfunction," Hypertension, vol. 54, no. 3, pp. 619-624, 2009.

[131] C. A. Gunnett, D. D. Lund, F. M. Faraci, and D. D. Heistad, "Vascular interleukin-10 protects against LPS-induced vasomotor dysfunction," American Journal of Physiology-Heart and Circulatory Physiology, vol. 289, no. 2, pp. H624-H630, 2005.

[132] L. Gullestad, J. Kjekshus, J. K. Damås, T. Ueland, A. Yndestad, and P. Aukrust, "Agents targeting inflammation in heart failure," Expert Opinion on Investigational Drugs, vol. 14, no. 5, pp. 557566, 2005.

[133] R. M. Patel and S. T. Shulman, "Kawasaki disease: a comprehensive review of treatment options," Journal of Clinical Pharmacy and Therapeutics, vol. 40, no. 6, pp. 620-625, 2015.

[134] J. C. Burns and A. Franco, "The immunomodulatory effects of intravenous immunoglobulin therapy in Kawasaki disease," Expert Review of Clinical Immunology, vol. 11, no. 7, pp. 819-825, 2015.

[135] B. P. Olivieri, R. Vasconcellos, A. Nóbrega, P. Minoprio, S. V. Kaveri, and T. C. Araújo-Jorge, "Intravenous immunoglobulin increases survival time in the acute phase of experimental Chagas disease," Parasite Immunology, vol. 32, no. 6, pp. 464469, 2010. 
[136] P. Aukrust, A. Yndestad, T. Ueland, J. K. Damås, S. S. Frøland, and L. Gullestad, "The role of intravenous immunoglobulin in the treatment of chronic heart failure," International Journal of Cardiology, vol. 112, no. 1, pp. 40-45, 2006.

[137] B. D. Singer, L. S. King, and F. R. D’Alessio, "Regulatory T cells as immunotherapy," Frontiers in Immunology, vol. 5, article 46, 2014.

[138] A. J. Beres and W. R. Drobyski, "The role of regulatory T cells in the biology of graft versus host disease," Frontiers in Immunology, vol. 4, article 163, Article ID Article 163, 2013.

[139] S. B. Felix, D. Beug, and M. Dörr, "Immunoadsorption therapy in dilated cardiomyopathy," Expert Review of Cardiovascular Therapy, vol. 13, no. 2, pp. 145-152, 2015.

[140] D. Bulut, G. Creutzenberg, and A. Mügge, "The number of regulatory $\mathrm{T}$ cells correlates with hemodynamic improvement in patients with inflammatory dilated cardiomyopathy after immunoadsorption therapy," Scandinavian Journal of Immunology, vol. 77, no. 1, pp. 54-61, 2013.

[141] D. Bulut, M. Scheeler, T. Wichmann, J. Börgel, T. Miebach, and A. Mügge, "Effect of protein A immunoadsorption on $\mathrm{T}$ cell activation in patients with inflammatory dilated cardiomyopathy," Clinical Research in Cardiology, vol. 99, no. 10, pp. 633-638, 2010.

[142] C. S. Garris, V. A. Blaho, T. Hla, and M. H. Han, "Sphingosine1-phosphate receptor 1 signalling in $\mathrm{T}$ cells: trafficking and beyond," Immunology, vol. 142, no. 3, pp. 347-353, 2014.

[143] M.-G. Kim, S. Y. Lee, Y. S. Ko et al., " $\mathrm{CD} 4^{+} \mathrm{CD} 25^{+}$regulatory $\mathrm{T}$ cells partially mediate the beneficial effects of FTY720, a sphingosine-1-phosphate analogue, during ischaemia/reperfusion-induced acute kidney injury," Nephrology Dialysis Transplantation, vol. 26, no. 1, pp. 111-124, 2011.

[144] Y. Liu, J. Jiang, H. Xiao et al., "The sphingosine-1-phosphate receptor agonist FTY720 and its phosphorylated form affect the function of CD4+CD25+ T cells in vitro," International Journal of Molecular Medicine, vol. 30, no. 1, pp. 211-219, 2012.

[145] D. C. Miller, K. B. Whittington, D. D. Brand, K. A. Hasty, and E. F. Rosloniec, "The CII-specific autoimmune T-cell response develops in the presence of FTY720 but is regulated by enhanced Treg cells that inhibit the development of autoimmune arthritis," Arthritis Research \& Therapy, vol. 18, no. 1, article 8, 2016.

[146] S. SehraWat and B. T. Rouse, "Anti-inflammatory effects of FTY720 against viral-induced immunopathology: role of druginduced conversion of T cells to become Foxp $3^{+}$regulators," Journal of Immunology, vol. 180, no. 11, pp. 7636-7647, 2008.

[147] Z. X. Wang, C. Q. Wang, X. Y. Li, Y. Ding, G. K. Feng, and X. J. Jiang, "Changes of naturally occurring $\mathrm{CD} 44^{+} \mathrm{CD} 25^{+} \mathrm{FOXP}^{+}$ regulatory $\mathrm{T}$ cells in patients with acute coronary syndrome and the beneficial effects of atorvastatin treatment," International Heart Journal, vol. 56, no. 2, pp. 163-169, 2015.

[148] C. J. Dwyer, N. C. Ward, A. Pugliese, and T. R. Malek, "Promoting immune regulation in type 1 diabetes using lowdose interleukin-2," Current Diabetes Reports, vol. 16, article 46, 2016.

[149] D. Klatzmann and A. K. Abbas, "The promise of low-dose interleukin-2 therapy for autoimmune and inflammatory diseases," Nature Reviews Immunology, vol. 15, no. 5, pp. 283-294, 2015.

[150] J. Koreth, H. T. Kim, K. T. Jones et al., "Efficacy, durability, and response predictors of low-dose interleukin-2 therapy for chronic graft-versus-host disease," Blood, vol. 128, no. 1, pp. 130137, 2016.
[151] J. Koreth, K.-I. Matsuoka, H. T. Kim et al., "Interleukin-2 and regulatory T cells in graft-versus-host disease," The New England Journal of Medicine, vol. 365, no. 22, pp. 2055-2066, 2011.

[152] M. D. McHugh, J. Park, R. Uhrich, W. Gao, D. A. Horwitz, and T. M. Fahmy, "Paracrine co-delivery of TGF- $\beta$ and IL-2 using CD4-targeted nanoparticles for induction and maintenance of regulatory T cells," Biomaterials, vol. 59, pp. 172-181, 2015.

[153] K. K. Witte, R. Byrom, J. Gierula et al., "Effects of vitamin D on cardiac function in patients with chronic HF: the VINDICATE study," Journal of the American College of Cardiology, vol. 67, no. 22, pp. 2593-2603, 2016.

[154] C. E. Hayes, S. L. Hubler, J. R. Moore, L. E. Barta, C. E. Praska, and F. E. Nashold, "Vitamin D actions on $\mathrm{CD}^{+}{ }^{+} \mathrm{T}$ cells in autoimmune disease," Frontiers in Immunology, vol. 6, article 100, 2015.

[155] M. Sottili, L. Cosmi, E. Borgogni et al., "Immunomodulatory effects of BXL-01-0029, a less hypercalcemic vitamin D analogue, in human cardiomyocytes and T cells," Experimental Cell Research, vol. 315, no. 2, pp. 264-273, 2009.

[156] J. Zhou, P. C. Y. Tang, L. Qin et al., "CXCR3-dependent accumulation and activation of perivascular macrophages is necessary for homeostatic arterial remodeling to hemodynamic stresses," The Journal of Experimental Medicine, vol. 207, no. 9, pp. 1951-1966, 2010.

[157] X. Clemente-Casares, J. Blanco, P. Ambalavanan et al., "Expanding antigen-specific regulatory networks to treat autoimmunity," Nature, vol. 530, no. 7591, pp. 434-440, 2016.

[158] M. Déruaz, A. Frauenschuh, A. L. Alessandri et al., “Ticks produce highly selective chemokine binding proteins with antiinflammatory activity," The Journal of Experimental Medicine, vol. 205, no. 9, pp. 2019-2031, 2008. 


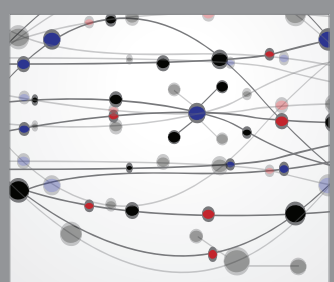

The Scientific World Journal
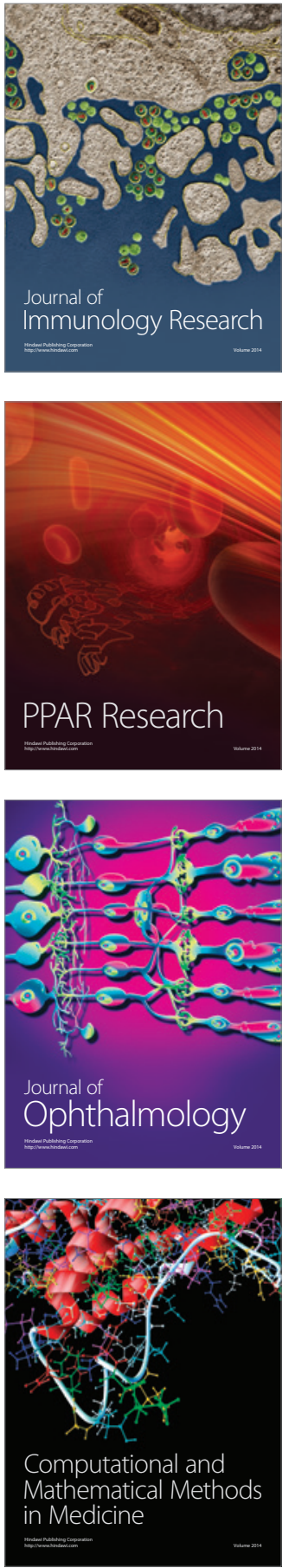

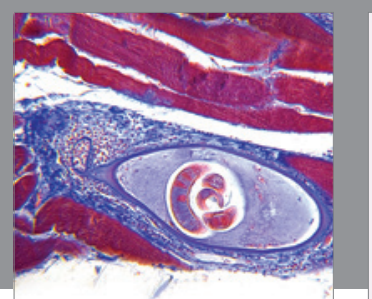

Gastroenterology Research and Practice

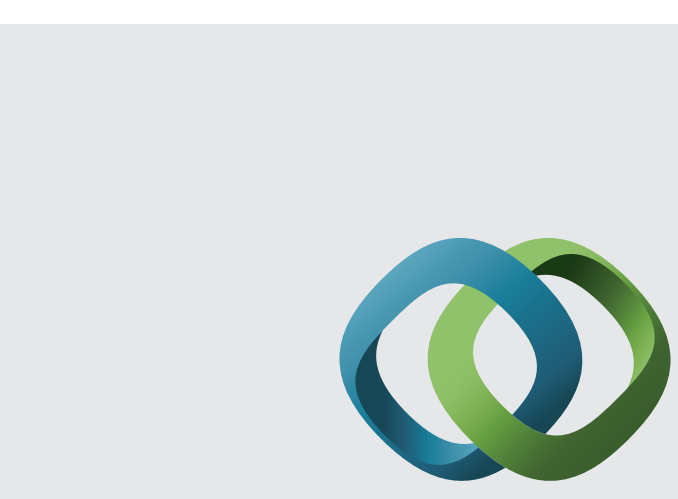

\section{Hindawi}

Submit your manuscripts at

http://www.hindawi.com
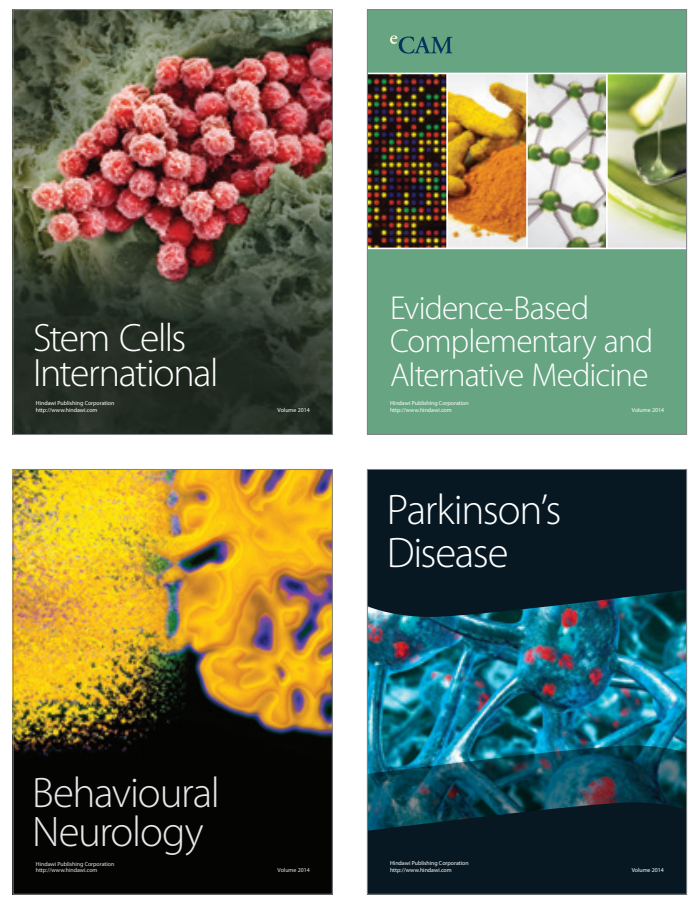
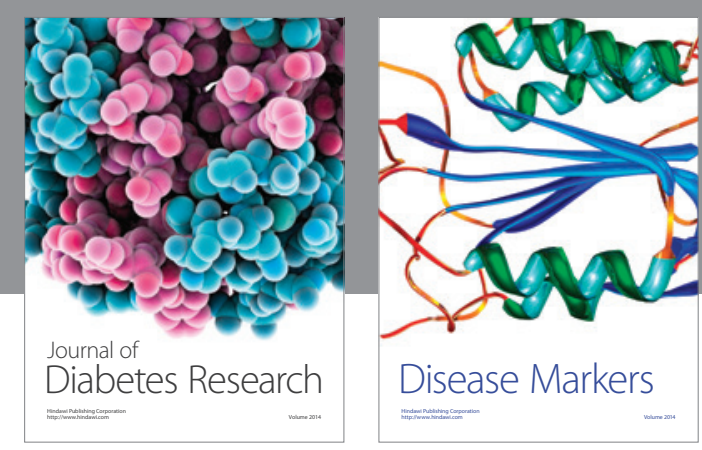

Disease Markers
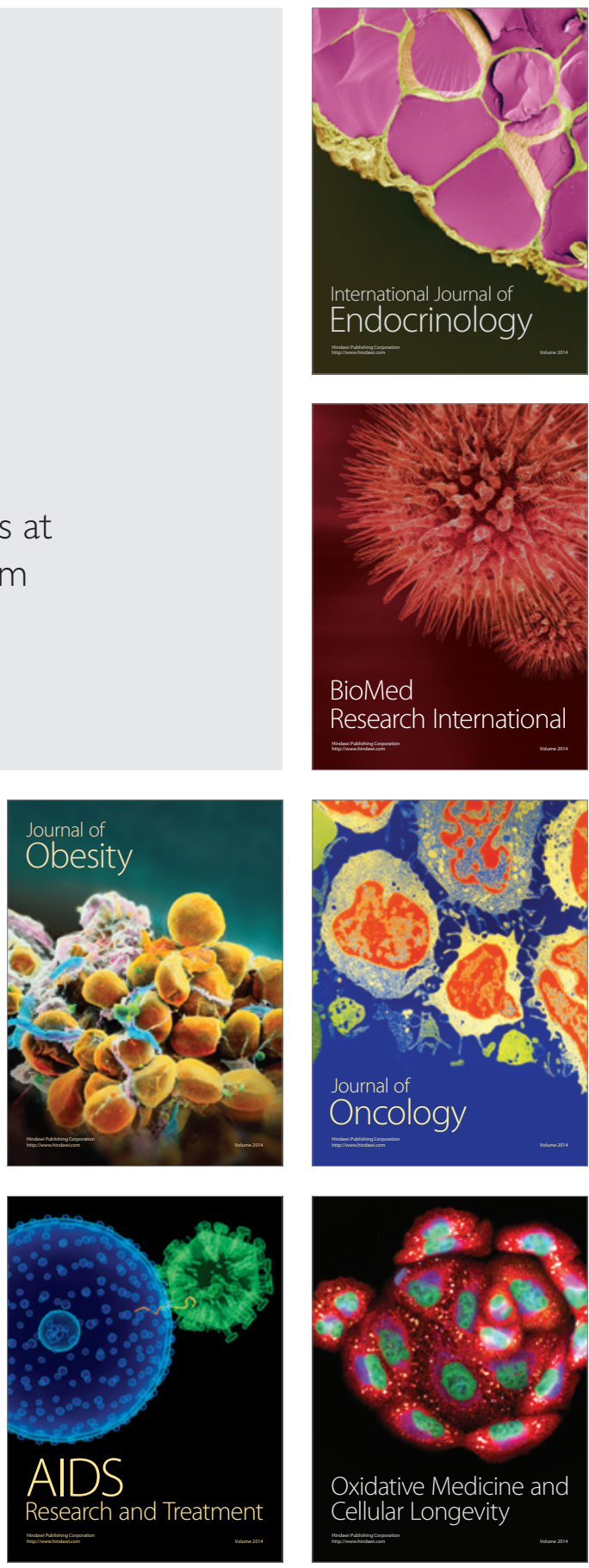